\title{
La Amazonía en disputa: agencias políticas y organizaciones indígenas de la Amazonía venezolana frente al Arco Minero del Orinoco
}

\author{
Julimar Mora Silva \\ Universidad Central de Venezuela (UCV), Caracas, Venezuela. \\ Email: julimar.mora@gmail.com \\ Fidel Rodríguez Velásquez \\ Instituto Venezolano de Investigaciones Científicas (IVIC), Caracas, Venezuela. \\ Email: fidelrodv@gmail.com
}

\begin{abstract}
Resumen: A partir del concepto de agencia y desde una sociología fundamentada en la teoría de la estructuración, analizamos el fenómeno de la participación política de las organizaciones indígenas amazónicas y sus respuestas al plan de desarrollo minero de la región amazónica de Venezuela conocido como el Arco Minero del Orinoco. Para ello, prestamos atención a los mecanismos de presión política y participación popular (asambleas, protestas, denuncias, comunicados, etc.) llevados adelante por las organizaciones indígenas entre 2016 y 2018, así mismo, a los resultados electorales en los territorios amazónicos desde 2013 hasta 2017. La realización de este trabajo fue posible a través de una estrategia multi método, considerando datos históricos, observación participante y entrevistas con líderes indígenas, intelectuales y participantes de los movimientos sociales. Los datos se organizaron siguiendo el método de Mapeo de Actores Clave. Concluimos que el Arco Minero del Orinoco representó una ruptura en el plano político y electoral de las organizaciones indígenas con el chavismo, en el marco de una intensificación del extractivismo minero en la Amazonía venezolana.
\end{abstract}

Palabras clave: Arco Minero del Orinoco, Amazonía, organizaciones indígenas, agencia, participación política.

\section{The Amazon in dispute: political agencies and indigenous organizations of the Venezuelan Amazon against the Orinoco Mining Arc}

\begin{abstract}
Starting from the concept of agency and from a sociology based on the theory of structuring, we analyze the phenomenon of political participation of Amazonian indigenous organizations and their responses to the mining development plan of the Amazonian region of Venezuela known as the Orinoco Mining Arc. For this, we pay attention to the mechanisms of political pressure and popular participation (assemblies, protests, denunciations, statements, etc.) carried out by indigenous organizations between 2016 and 2018, as well as to the electoral results in the Amazon territories from 2013 to 2017. The realization of this work was possible through a multi-method strategy, considering historical data, participant observation and interviews with indigenous leaders, intellectuals and participants of social movements. The data were organized following the Key Actor Mapping method. We concluded that the Orinoco Mining Arc represented a rupture in the political and electoral sphere between indigenous organizations and chavismo, within the framework of an intensification of mining extractivism in the Venezuelan Amazon.
\end{abstract}

Keywords: Orinoco Mining Arc, Amazon, indigenous organizations, agency, political participation 


\section{Amazônia em disputa: agências políticas e organizações indígenas da Amazônia venezuelana contra o Arco Mineiro do Orinoco}

Resumo: A partir do conceito de agência e desde uma sociologia baseada na teoria da estruturação, analisamos o fenômeno da participação política das organizações indígenas da Amazônia e suas respostas ao plano de desenvolvimento mineiro para a região amazônica da Venezuela conhecido como o Arco Mineiro do Orinoco. Para fazer isso, devimos prestar atenção aos mecanismos de pressão política e participação popular (assembleias, protestos, denuncias, relatórios, comunicados de imprensa, etc.) realizadas por organizações indígenas entre 2016 e 2018, como também nos resultados das eleições nos territórios amazônicos desde 2013 até 2017. A realização deste trabalho foi possível através de uma estratégia multimétodo, considerando dados históricos, observação participante e entrevistas com lideranças indígenas, intelectuais e participantes de movimentos sociais. Os dados foram organizados seguindo o método de Mapeamento de Atores-Chave. Concluímos que o Arco Mineiro do Orinoco representou uma ruptura no plano político e eleitoral das organizações indígenas com o Chavismo, no marco de uma intensificação do extrativismo mineiro na Amazônia venezuelana.

Palavras-chave: Arco Mineiro do Orinoco, Amazônia, organizações indígenas, agência, participação política.

\section{Introducción}

Las agencias políticas de los pueblos indígenas de la Amazonía venezolana y su relación con los conflictos socioambientales que impactaron los territorios amazónicos en el curso del siglo XXI, han estado mediadas por el sostenimiento de formas de organización tradicionales (coaliciones multiétnicas), el impacto de misiones religiosas y la experiencia indígena en los proyectos de modernización impulsados por el Estado venezolano y el sector privado, nacional y transnacional, durante la segunda mitad del siglo XX. La aplicación de políticas neoliberales en toda América Latina, especialmente a partir de la década de los 80, generó un panorama convulso que complicó las relaciones entre indígenas, propietarios de las tierras, empresas privadas e instituciones estatales. De esta forma, episodios de violencia como el caso “Zingg-Piaroa” (1984) en Venezuela y la masacre de "Haximú" (1993) en la frontera Venezuela-Brasil, radicalizaron las fricciones existentes entre los indígenas de la Amazonía, los Estados nacionales y el sector privado asociado a las actividades mineras, ganaderas y energéticas (Biord Castillo, 2010); a la vez que encausaron las demandas de los pueblos indígenas a la búsqueda de aliados políticos en sectores de corte progresista, con visiones más abiertas e inclusivas, y apalancadas en modelosde desarrollo alternativos a los implementados en América Latina a finales del siglo pasado. ${ }^{1}$

En este escenario, comenzaron a articularse coaliciones indígenas en toda la región amazónica. En el caso venezolano destacó la creación de confederaciones multiétnicas y partidos regionales como la Unión Makiritare Alto Ventuari (UMAV) creada en 1972, la Organización Indígena Piaroa "Uhuottuja" del Sipapo (OIPUS) creada a mediados de los años80; la cooperativa indígena Shaponos Unidos Yanomami Alto Orinoco (SUYAO) creada en 1986; la Organización Regional de Pueblos Indígenas de Amazonas (ORPIA)creada en 1993; la Organización Indígena Ye’kwana-Sanemá (KUYUJANI) creada en 1996; el partido político Pueblos Unidos Multiétnicos de Amazonas (PUAMA) creado en 1997, entre otras (Palau, 2001). ${ }^{2}$ Simultáneamente, en 1989 se fundó un partido político de alcance nacional, el Consejo Nacional Indio de Venezuela (CONIVE),que vino a potenciar la articulación de los sectores indígenas en toda Venezuela y a promover su participación en la vida política nacional. En principio, el común denominador de todas estas organizaciones fue la creación de estructuras autónomas que no funcionaran como apéndices de los partidos políticos tradicionales ?como Acción Democrática (AD) y Comité de Organización Política Electoral Independiente (COPEI)³ ?,ni de los partidos de izquierda ?como el Movimiento al Socialismo (MAS), Partido Comunista de Venezuela (PCV) y Movimiento Electoral del Pueblo (MEP)? promoviendo una agenda propia alineada con las demandas e intereses específicos de los pueblos indígenas de la región amazónica.

En este marco, se celebró el primer (1993-1995), segundo (1995-1998) y tercer (2002-2003) congreso ORPIA donde confluyeron miembros de diecinueve pueblos indígenas del área amazónica, así como varios de sus líderes y organizaciones locales. Los temas propuestos en estos congresos fueron reflejo de los avances de la agencia indígena en los asuntos nacionales, partiendo de discusiones centradas en problemas y soluciones locales (relativos a la organización, tenencia de la tierra, salud, educación, protección del medio ambiente y 
respeto de los Derechos Humanos); hasta consolidar una agenda que posicionó a representantes de estas organizaciones en el proceso constituyente celebrado en 1999, logrando el apoyo político de la coalición de gobierno liderada por el recién electo presidente Hugo Chávez (Tillet y Moncada, 2017; Caballero Arias, 2018). Los alcances de esta agenda fueron notables (1) por primera vez en la historia republicana de Venezuela se incluyó un capítulo dedicado al reconocimiento de los derechos indígenas en la Constitución; y (2) se avanzó en un cuerpo legislativo abocado exclusivamente a los asuntos indígenas: Ley Orgánica de Pueblos y Comunidades Indígenas (2005), Ley de Idiomas Indígenas (2008), Ley de Patrimonio Cultural de los Pueblos y Comunidades Indígenas (2009) y Ley del Artesano y Artesana Indígena (2010). ${ }^{8}$

En función de ello convenimos que la agencia política indígena logró influir decisivamente en el discurso político del chavismo y de manera parcial en las políticas de Estado implementadas en Venezuela durante los gobiernos de Hugo Chávez (1999-2013), puesto que el nuevo marco jurídico reconoció los derechos indígenas; a la vez que sujetos del mundo indígena se conectaron directamente con instituciones del Estado, tanto en cargos públicos de elección popular (diputados a la Asamblea Nacional, concejalías, etc.) como en cargos burocráticos designados en espacios como ministerios e institutos. Sin embargo, la relación de las comunidades indígenas con el gobierno de Hugo Chávez y la institucionalidad del Estado no se tradujo del todo en el empoderamiento directo de los indígenas sobre su territorio y destino pues, derechos constitucionales como la demarcación de tierras y la consulta previa fueron cercenados de manera sistemática; a lo que se suma la cooptación de dirigentes indígenas y estructuras tradicionales que en muchos casos fueron perdiendo autonomía ante los intereses del Estado. De esta forma, optamos por lecturas heterodoxas similares a las planteadas por autores como Arvelo-Jiménez (1984; 1987; 2013), Van Cott (2002), Oldham (2003) y Bracho (2008) las cuales nos permitirán caracterizarlas tensiones entre el Estado y las organizaciones indígenas de la Amazonía venezolana en dirección de "abajo hacia arriba”, es decir, en oposición a lecturas donde el ejercicio político indígena es resultado de un direccionamiento desde el Estado y no viceversa.

A partir de ello, utilizaremos las ideas propuestas por Mitnick (2015) quien define la agencia (agency) como la potencialidad de ciertos actores/organizaciones para lograr objetivos específicos conforme con sus capacidades políticas de decidir y hacer en un contexto. A esto se suman las consideraciones de Giddens (2014) quien, desde una sociología fundamentada en la teoría de la estructuración, hace énfasis en la direccionalidad de las agencias sociales hacia fines orientados a la transformación de la realidad de los actores los cuales, se consideran "agentes" en la medida que son coparticipes en la construcción de su destino. La aplicación de este concepto en el análisis de las actuaciones indígenas en América Latina, especialmente en el curso del siglo XXI, constituye un reto que vale la pena tomar pues, la instalación de gobiernos progresistas en países como Argentina, Bolivia, Brasil, Ecuador, Nicaragua, Uruguay y Venezuela, trajo consigo un clima ideológico favorable a visiones que han intentado explicar las movilizaciones indígenas de los últimos años como una consecuencia/ resultado de las políticas de Estado coligadas a los proyectos de izquierda (Svampa, 2010), y no como una causalidad de las nuevas formas de hacer política en el marco de un emergente pluralismo étnico en numerosos contextos de América Latina.

Contrario a esto, pensamos que las agencias políticas de los pueblos indígenas de la Amazonía venezolana responden a una continuidad histórica que, en el corto plazo, es posible rastrear en las asociaciones étnicas y coaliciones multiétnicas que se formaron como respuesta a la intensiva intervención del Estado y el sector privado entre las décadas 70 y 90; y que, en el largo plazo, tiene raíces profundas en los tradicionales sistemas de alianza interétnicas del norte amazónico conocidos por la tradición antropológica como el Sistema de Interdependencia Regional del Orinoco (SIRO). ${ }^{4}$ La recreación de este sistema ha sido una respuesta histórica de los indígenas amazónicos a amenazas externas (generalmente asociadas a incursión en sus territorios), replicándose en reiteradas ocasiones durante el período colonial y, recientemente, ante la avanzada del capital privado y del Estado en los a partir de los años 70, y la puesta en marcha del AMO en años recientes. Este sistema se ha creado y recreado entre los grupos indígenas del norte amazónico siguiendo un principio de complementariedad política que, en algunos casos, favoreció el intercambio y ayuda mutua, mientras en otros favoreció la fragmentación de los grupos sin que este hecho representase una amenaza a la reciprocidad y autonomía de los pueblos y organizaciones locales al interior del sistema (Arvelo-Jiménez, Morales y Biord, 1989; Arvelo-Jiménez y Biord, 1994). 
Desde esta premisa, buscaremos analizar el fenómeno de la participación política de las organizaciones amazónicas y sus respuestas al plan de desarrollo minero de la región amazónica de Venezuela conocido con el nombre de Arco Minero del Orinoco (AMO), partiendo de un análisis integrado de las agencias indígenas en dos dimensiones. Una primera, centrada en mecanismos de presión política y participación popular (asambleas, protestas, denuncias, comunicados, etc.); y una segunda, preocupada por las repercusiones del movimiento indígena en el escenario político nacional, específicamente, en lo relativo a los procesos electorales locales. Con ello, esperamos mostrar que las agencias políticas de las organizaciones indígenas de la Amazonía han sido dinámicas y flexibles ante el reto que supone hacer frente al AMO, optando por (1) estrategias de integración y segregación intra e interétnica, (2) mecanismos de mediación con el mundo criollo a fin de aumentar su visibilidad y (3) apropiación de tácticas políticas externas a su patrimonio cultural.

\section{Consideraciones metodológicas}

Para la realización de este trabajo se utilizó una estrategia multi método, considerando (1) datos históricos referidos a los comicios electorales, regionales y municipales, realizados en Venezuela entre los años 2013 y 2017 publicados por el Consejo Nacional Electoral (CNE);notas de prensa relativas a la movilización indígena frente al AMO entre los años 2016 y 2018; y boletines epidemiológicos emitidos por la Organización Mundial de la Salud (OMS) y Organización Panamericana de la Salud (OPS). Así mismo, datos provistos por (2) la observación participante en reuniones, asambleas y mesas de trabajo llevadas adelante por las organizaciones indígenas durante los años 2017 y 2018; y (3) entrevistas con líderes indígenas, intelectuales y militantes de movimientos sociales pro indigenistas en el curso del mismo periodo. Todos estos datos fueron organizados siguiendo el método de Mapeo de Actores Clave (MAC)que permitió esbozar un listado las organizaciones indígenas y sus aliados en la lucha contra el AMO, así como sus acciones, objetivos y perspectivas de futuro inmediato.

\section{El AMO: anatomía de un problema Caracterización y contexto de surgimiento}

En 2014 los precios internacionales del petróleo experimentaron una dramática caída que se prolongó hasta 2016 (Smilde, 2015; Puente, 2016). A partir de entonces, el presidente de la república Nicolás Maduro impulsó la promoción de la minería en la región de Guayana acelerando la militarización de los territorios indígenas ubicados al interior de la cuenca amazónica. En simultáneo, puso en vigencia la Ley de Regionalización Integral para el Desarrollo Socioproductivo de la Patria (2014) la cual sentenció la legalidad de "zonas económicas especiales” creadas como respuesta a la recesión económica de Venezuela en los últimos años, posicionando la "minería ecológica" como un pilar de las políticas de desarrollo emergentes y trayendo consigo notables contradicciones con los pueblos indígenas y movimientos ecologistas (Terán Mantovani, 2016).

En 2016 se renovaron las condiciones legales para reservar al Estado venezolano el derecho a la exploración y explotación delos recursos minerales estratégicos contenidos en la Amazonía, proceso que había iniciado de forma más conservadora con la aprobación del presidente Hugo Chávez a los proyectos de la Faja Petrolífera del Orinoco y el Arco Minero de Guayana en 2011. Concretamente, el 24 de febrero de 2016 se creó por decreto oficial la Zona de Desarrollo Estratégico Nacional Arco Minero del Orinoco, acompañado de otro decreto que puso en funcionamiento el Ministerio del Poder Popular para el Desarrollo Minero Ecológico el 9 de junio del mismo año (Cannon y Brown, 2017; Valladares y Sandia, 2017). Según palabras del presidente, ambas medidas estuvieron llamadas a hacer frente "(...) a la realidad económica nacional ante la caída estrepitosa de los precios de los hidrocarburos” (Prensa Presidencial, 2016), poniendo a disposición de actividades mineras un total de 111.843,70 km² de los territorios amazónicos de Venezuela, equivalente al 12,2\% del territorio nacional.

El AMO se encuentra ubicado en la zona sur del río Orinoco, específicamente, en el extremo norte de los estados Bolívar y Amazonas, y al sur de Delta Amacuro, comprendiendo cuatro áreas de explotación y un bloque especial de los que se espera extraer commodities como oro, diamante, coltán, hierro, cobre y bauxita.

En el interior de sus límites quedaron comprometidas (1) múltiples Áreas bajo Régimen de Administración Especial (ABRAE) como parques nacionales, reservas forestales y monumentos naturales; así como (2) varios 
de los afluentes de agua dulce más importantes de Venezuela; (3) una gran diversidad de especies animales y vegetales; y (4) numerosas comunidades indígenas de los pueblos amazónicos warao, akawayo, éñepa, pumé, mapoyo, kariña, arawak, piaroa, pemón, ye’ kwana, hoti, jivi y sanemá (Ruiz, 2018).

\section{El AMO como ruptura del proyecto político del chavismo con las organizaciones indígenas y movimientos sociales}

El AMO representó una ruptura en la relación del Estado con las organizaciones indígenas y sus aliados en los movimientos sociales pro indigenistas y pro ambientalistas (E-OI-MS); aunque debe destacarse que esta ruptura es una continuidad de tensiones anteriores como las que se suscitaron entorno a los proyectos de explotación de oro y diamante en la Reserva Forestal de Imataca en 2004 y la ampliación de la explotación de carbón en la cuenca del río Guasare y sierra de Perijá en 2006 (García-Guadilla, 2009; Krzywicka, 2011) (para una lista detallada de los conflictos socioambientales en Venezuela durante el período 2019-2017 véase a Terán Mantovani, 2018).

Sin embargo, es necesario advertir que estas tensiones fueron controladas y administradas durante los gobiernos de Hugo Chávez pues, estuvieron mediadas por atenuantes políticos como (1) las crecientes cuotas de participación de indígenas en las instituciones del Estado producto de una expansión institucional caracterizada por un incremento del sector público respecto al privado (Alès, 2018); ideológicos como (2) un discurso oficial favorable a las reivindicaciones históricas de los pueblos indígenas que hizo participe a casi todas las organizaciones amazónicas del proyecto político del chavismo (Angosto, 2008); y sociales como (3) la enorme inversión en políticas públicas dirigidas a los pueblos indígenas con la creación de la misión Guaicaipuro en 2003, y posteriormente del Ministerio del Poder Popular para Pueblos indígenas en 2007 (Caballero Arias, 2007). Todos estos factores apalancados en una renta económica sin precedentes consecuencia del crecimiento sostenido de los precios del petróleo en mercados internacionales (recuérdese que desde 1999 hasta 2014 Venezuela recibió 873.000 millones de dólares en ingresos por concepto de exportaciones petroleras).

En contraste, el panorama en torno el AMO ha sido radicalmente diferente. Condiciones contrapuestas como (1) El cambio de las prioridades del Estado que, hasta la fecha había manifestado tener como prioridad la defensa de los derechos indígenas y la demarcación de sus territorios, a prioridades centradas en la identificación y cuantificación de las reservas minerales y la puesta en marcha de proyectos extractivos que le permitiesen su comercialización en mercados del exterior; (2) el cambio del perfil de los actores políticos con competencia en la Amazonía venezolana destacando una creciente participación de militares en puestos de gobierno, en sustitución de los tradicionales líderes indígenas y militantes de izquierda que habían dominado la escena; (3) la presencia de compañías extranjeras en la región que en el pasado habían sido expulsadas por el mismo gobierno chavista (destaca el caso de la empresa canadiense Gold Reserve); y (4) la sustitución de políticas estructurales como demarcación de tierras indígenas, participación política, educación intercultural bilingüe, entre otras, por estímulos coyunturales asignados discrecionalmente como cajas con alimentos, bonos y aumentos salariales contingentes; los cuales aceleraron las reacciones negativas de las organizaciones y liderazgos indígenas de la Amazonía a las "nuevas” políticas de Estado.

\section{El AMO y su impacto negativo en las poblaciones indígenas de la Amazonía en Venezuela}

En líneas generales, las consecuencias del AMO entre las poblaciones indígenas del norte amazónico no pueden calificarse de otra forma diferente de catastróficas. Desplazamientos territoriales, reiterados episodios de violencia y deterioro en las condiciones de salud constituyen algunos de los problemas sociales más urgentes. Los casos de paludismo en Venezuela para 2017 (319.765 casos) fueron muy superiores a la media anual registrada durante los últimos veintinueve años (cincuenta mil casosaprox.), reflejando un incremento mayor al 600\%con una alta incidencia en los territorios involucrados en el AMO. Lo mismo ocurrió con el número de infectados por sarampión que incrementó 5.643\% entre los años2016 y 2018, siendo los estados Bolívar y Delta Amacuro dos de las entidades más afectadas(véase la tabla 1). Las consecuentes migraciones y el incremento de los pozos y excavaciones dejados por la minería a cielo abierto facilitaron las condiciones para la propagación de enfermedades infecciosas como el paludismo, el sarampión, la difteria, la tuberculosis y los riesgos de contaminación por el uso de cianuro; siendo el estado Bolívar la zona más afectada por la minería y múltiples enfermedades de las cuales no se tiene registro exacto (OPS y OMS, 2017). 
Tabla 1.

Número de afectados por enfermedades infecciosas en Venezuela y las entidades involucradas en el $\mathrm{AMO}^{5}$

\begin{tabular}{ccccccccc}
\hline Región & \multicolumn{2}{c}{ VENEZUELA (nacional) } & \multicolumn{2}{c}{ AMAZONAS } & \multicolumn{2}{c}{ BOLÍVAR } & \multicolumn{2}{c}{ DELTA AMACURO } \\
\hline Infección & Paludismo & Sarampión & Paludismo & Sarampión & Paludismo & Sarampión & Paludismo & Sarampión \\
\hline $\mathbf{2 0 1 6}$ & 240.613 & $0[\mathrm{a}]$ & Sin datos & 0 & Sin datos & 0 & Sin datos & 0 \\
\hline $\mathbf{2 0 1 7}$ & $319.765[\mathrm{~b}]$ & 727 & 52.471 & Baja prioridad & 205.215 & $596[\mathrm{c}]$ & Sin datos & Alta prioridad \\
\hline $\mathbf{2 0 1 8}$ & Sin datos & $5.643[\mathrm{~d}]$ & Sin datos & 124 & Sin datos & \multirow{2}{*}{ Baja prioridad[e] } & Sin datos & 343 \\
\hline
\end{tabular}

Fuente: Elaboración propia a partir de los datos de la OPS y OMS.

A los problemas de salud y desasistencia social se sumó el creciente intervencionismo militar y paraestatal que potenció el auge de la minería ilegal trayendo como consecuencia un reordenamiento de la población y un incremento de los episodios de violencia en zonas mineras como Tumeremo, El Callao, El Dorado, Las Claritas, El Manteco, El Palmar, Guasipati, Maripa y Canaima en el estado Bolívar (véase los focos de violencia en la región amazónica de Venezuela señalados en la figura 1). Aunque no existen cifras oficiales, considerables sectores de la población se movilizaron al estado Bolívar atraídos por el boom minero en el norte de la Amazonía, cuestión que continúa profundizándose consecuencia de la recesión económica que experimenta Venezuela desde mediados de 2014. La movilización interna coincidió con el desplazamiento forzado de centenares de indígenas hacia las áreas de frontera con Colombia y Brasil (UNHCR, 2018), quienes se vieron confinados por las consecuentes epidemias; la reducción radical de las políticas públicas en materia de salud, educación y alimentación; y una expansión sin precedentes de episodios de violencia asociados a actividades militares y paraestatales en contextos mineros. ${ }^{6}$

Figura 1.

Territorios indígenas, zonas mineras y focos de violencia en el AMO

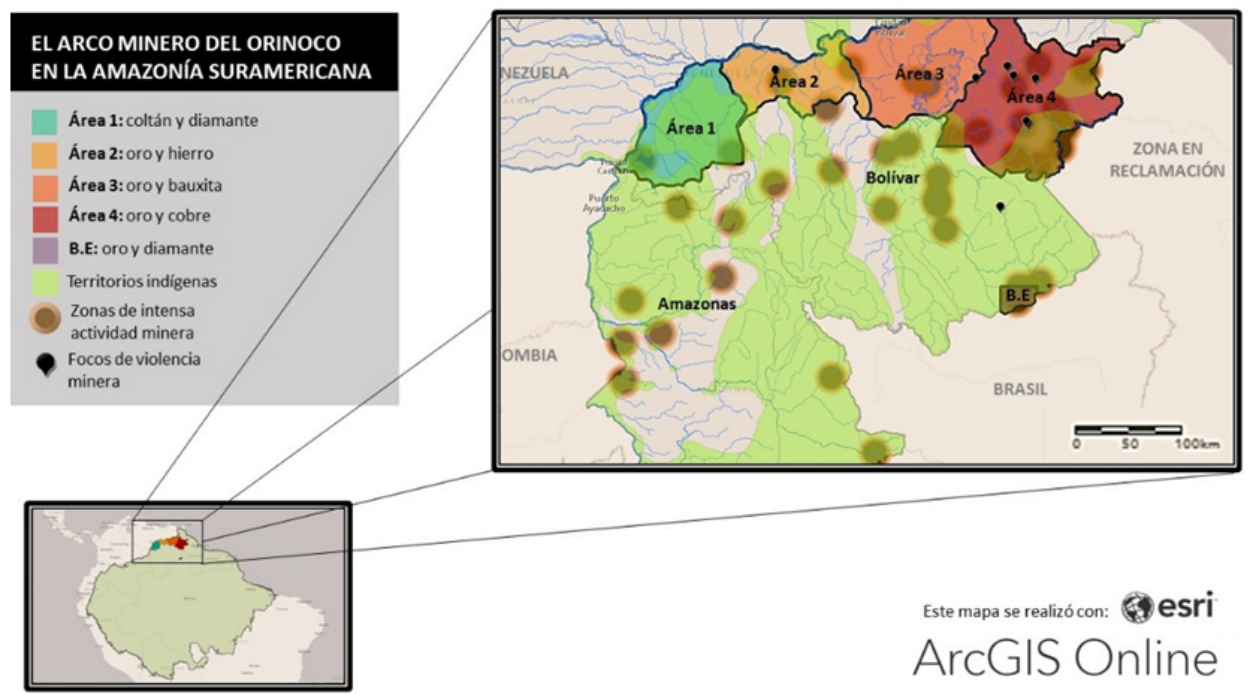

Fuente: Elaboración propia. 


\section{Articulación y mecanismos de presión de las organizaciones indígenas frente al AMO}

Las agencias políticas de las organizaciones indígenas en torno al AMO se produjeron siguiendo patrones de articulación horizontal, con base en el intercambio indiferenciado a largo plazo (como es el caso de las articulaciones interétnicas entre las organizaciones indígenas amazónicas), y vertical, con base en la relación inmediata costo-beneficio (como es el caso de las articulaciones con partidos políticos criollos)que potenciaron su alcance en distintos momentos y niveles. El seguimiento de sus actuaciones mostró una tendencia hacia modelos de participación alrededor de escenarios locales. Reuniones, encuentros y asambleas, desde el norte del río Caura hasta Canaima en el estado Bolívar, funcionaron como mecanismos de articulación permanente para hacer frente al problema minero y sus consecuencias desde el ámbito territorial. Organizaciones indígenas como ORPIA, KUYUJANI, OIPUS, OIYAPAM, Coordinadora de Organizaciones Indígenas de la Amazonía Venezolana (COIAM), Consejo de Caciques Generales del Pueblo Pemón (CCGPP), Confederación Indígena Bolivariana de Amazonas (COIBA), Federación Indígena del Estado Bolívar (FIEB), entre otras, ${ }^{7}$ promovieron espacios de integración entre las comunidades amazónicas afectadas por la minería, a la vez que fortalecieron el rol político de las organizaciones indígenas en el marco dela crisis de la Venezuela progresista. Este último aspecto se vio reflejado en los comunicados de rechazo de estas organizaciones los cuales apropiaron el cuerpo jurídico y discurso político, utilizado por el chavismo, para denunciar públicamente las contradicciones fácticas del proyecto chavista de corte "indigenista” y la puesta en marcha del AMO en los territorios de la Amazonía (véase la figura 2).

Figura 2.

Distribución en el tiempo de los comunicados, asambleas, recursos legales y protestas de las organizaciones indígenas al AMO

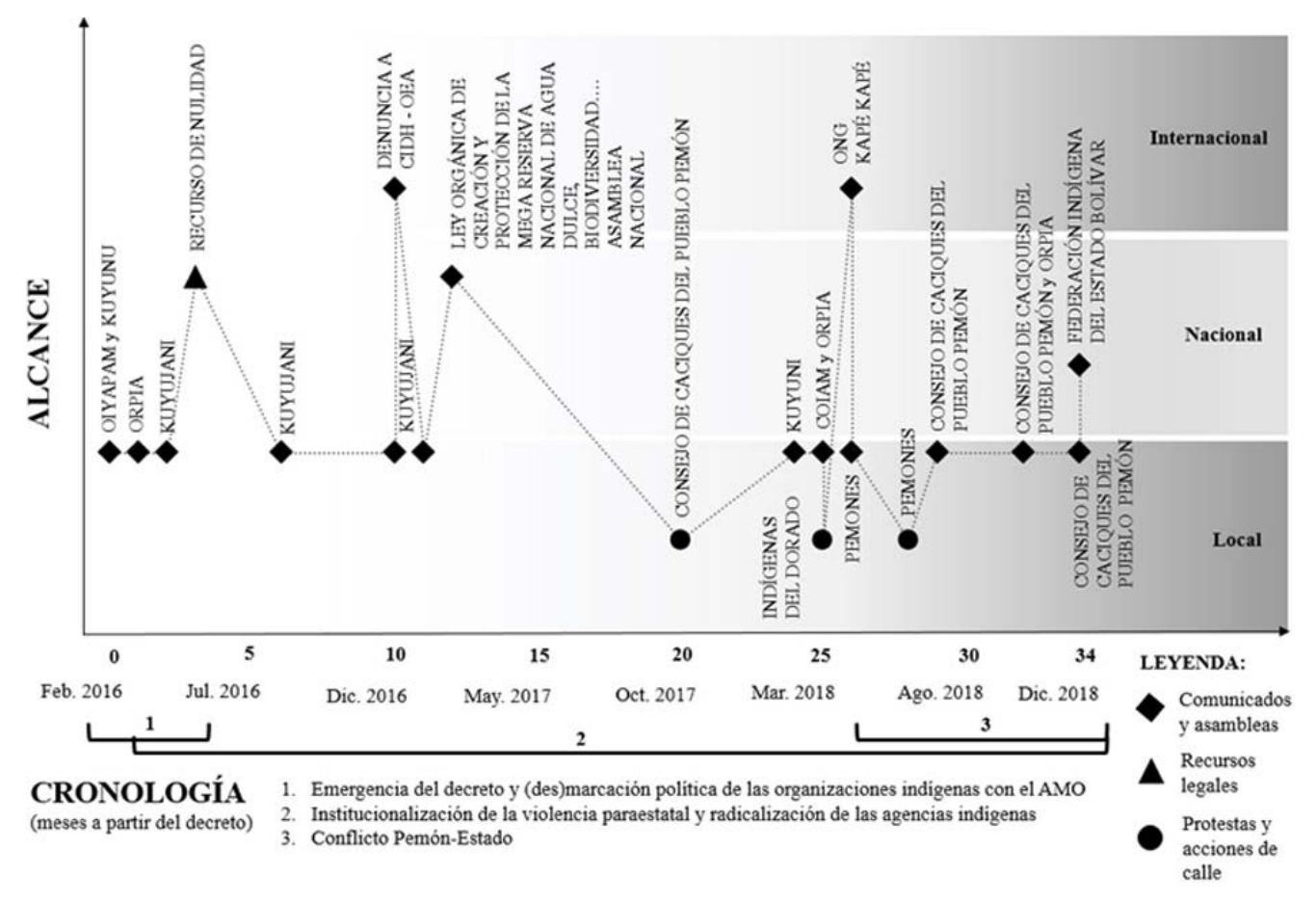

Fuente: Elaboración propia.

Simultáneamente, se produjeron protestas y acciones de calle que reforzaron los mecanismos de presión dirigidos desde los indígenas hacia el Estado. De esta forma, la emergencia de comunicados y protestas estuvo anclada a eventos específicos como desapariciones forzadas de indígenas, muerte de líderes comunitarios, 
agresiones contra mineros y abusos de poder por parte de los cuerpos de seguridad del Estado. La distribución en el tiempo de estas situaciones reflejó los altos y bajos de las tensiones presentes en las relaciones entre los poderes del Estado, los grupos para estatales y las organizaciones indígenas ante la profundización del extractivismo minero en la Amazonía. Sin embargo, con excepción de los casos donde operó una "partidización política” de las acciones de protesta, la mayoría de ellas tuvo un alcance a nivel local. Los casos con relevancia nacional e internacional dependieron de articulaciones más amplias entre las organizaciones indígenas con grupos de activistas, referentes académicos e intelectuales, ONG's por los Derechos Humanos, plataformas políticas con vocación partidista y medios de comunicación independientes los cuales sirvieron de aliados en su mediación con el escenario político más allá de los territorios amazónicos (véase la tabla 2).

Tabla 2.

Organizaciones aliadas al movimiento indígena contra el AMO

\begin{tabular}{ll}
\hline TIPO DE ALIADO & ORGANIZACIONES \\
\hline \multirow{3}{*}{ Activistas } & $\begin{array}{l}\text { Plataforma por la Nulidad del Decreto del Arco Minero del Orinoco, Frente Anti-minero de } \\
\text { Venezuela, el Grupo de Trabajo Socioambiental de la Amazonía Wataniba, Grupo de Trabajo } \\
\text { sobre Asuntos Indígenas (GTAI), Plataforma Ciudadana en defensa de la Constitución, Red } \\
\text { Ara, SOS Orinoco, entre otras. }\end{array}$ \\
\hline & $\begin{array}{l}\text { Instituciones académicas cono: Centro Gumilla, Centro de Estudios de la Realidad } \\
\text { Latinoamericana, Observatorio de Ecología Política de Venezuela (OEP), Universidad }\end{array}$ \\
& $\begin{array}{l}\text { Central de Venezuela (UCV), Universidad de Los Andes (ULA), Universidad Simón Bolivar } \\
\text { (USB), Universidad del Zulia (LUZ), Universidad de Carabobo (UC), Universidad Católica }\end{array}$ \\
& $\begin{array}{l}\text { Andrés Bello (UCAB), Universidad Nacional Experimental Indígena del Tauca (UNEIT), } \\
\text { Universidad Nacional Experimental de las Artes (UNEARTE), Universidad Centroccidental }\end{array}$ \\
& $\begin{array}{l}\text { Lisandro Alvarado (UCLA), Universidad Nacional Experimental de Guayana (UNEG), } \\
\text { Instituto Venezolano de Investigaciones Científicas (IVIC), Asociación de Arqueólogos y } \\
\text { Arqueólogas de Venezuela (AAAV), entre otras. Intelectuales como: Esteban Emilio } \\
\text { Mosonyi, Edgardo Lander, Héctor Navarro, Santiago Arconada, entre otros. }\end{array}$ \\
\hline \multirow{3}{*}{ ONG's } & $\begin{array}{l}\text { Provea, Centro de Investigaciones Ecológicas de Venezuela (CIEV), Kapé Kapé, Grupo } \\
\text { Ecológico San Pedro (GESP), Fundación Nativo, Sociedad Hominis Iura (SOHI), Laboratorio } \\
\text { de Paz, Sociedad Homo et Natura, entre otras. }\end{array}$ \\
\hline Plataformas políticas con & Anteriormente, afines al chavismo como Marea Socialista (MS) y el Partido Comunista de \\
orientación partidista & Venezuela (PCV). También de oposición como La Causa R (LCR), principalmente. \\
\hline Medios de comunicación & Aporrea y El Libertario. \\
\hline
\end{tabular}

Fuente: Elaboración propia.

Estas alianzas permitieron elevar la demanda indígena hacia espacios que potenciaron su visibilidad en el debate político nacional e internacional. Reiterados conversatorios en ambientes universitarios acompañados de protestas en espacios públicos e instituciones del Estado expandieron la resonancia de la denuncia indígena contra el AMO. De estas alianzas resultaron estrategias que permitieron elevar las denuncias de las organizaciones indígenas a instancias internacionales; ejemplo de esto lo constituyeron las audiencias que organizaciones como Provea, Laboratorio de Paz y GTAI organizaron ante la Comisión Interamericana de Derechos Humanos (CIDH)en diciembre de 2016, esto con el propósito de intensificar las presiones internacionales para hacer valer los derechos constitucionales dela consulta previa y demarcación de los territorios indígenas involucrados en el AMO; y posteriormente, la participación de ONG’s como Kapé Kapé en espacios políticos regionales como el Foro de los Pueblos Indígenas en el marco de la VIII Cumbre de las Américas a principios de 2018.Sin embargo, es necesario decir que la mayoría de estos espacios retroalimentaron los lazos entre un público militante, es decir, entre sectores tradicionalmente sensibles a los asuntos indígenas y ambientales, teniendo dificultades para posicionar las demandas contra el AMO como un problema del que debían ocuparse los sectores sociales que tradicionalmente no acompañan estas causas. Las razones de esto se atribuyen a que, en el marco de la crisis, (1) los problemas anteriormente exclusivos a los sectores vulnerables y minorías sociales se expandieron y diversificaron hacia el resto de la población, diluyendo la centralidad de las reivindicaciones indígenas 
frente al AMO; (2) los partidos de oposición al gobierno con mayor visibilidad presentaron el AMO como un conflicto de soberanía nacional y administración de los recursos por encima de una problemática específica de los pueblos indígenas; y (3) consecuencia de lo segundo, los principales medios de comunicación dieron fuerza a opiniones expresas por actores externos al mundo indígena, relegando su difusión a medios de comunicación alternativos o locales.

A manera de síntesis, planteamos tres momentos de la agencia política de las organizaciones indígenas frente al AMO:

\section{Primer momento: emergencia del decreto y (des)marcación política de las organizaciones indígenas con el AMO (febrero-mayo del 2016)}

A partir de febrero de 2016,la mayoría de las organizaciones indígenas publicaron pronunciamientos y comunicados de rechazo que las desmarcaron de las "nuevas" políticas extractivas impulsadas por el Estado en el marco de la crisis. Este hecho fue especialmente importante considerando que organizaciones indígenas relevantes como ORPIA y PUAMA constituyeron movimientos de base, afines o parte, del chavismo en los últimos veinte años. Dichos pronunciamientos visibilizaron las dislocaciones políticas entre E-OI-MS, a la vez que objetaron las estrategias mediáticas de voceros e instituciones del Estado que presentaron el AMO y la mega minería como una alternativa de desarrollo compatible con las demandas de las organizaciones indígenas y los movimientos sociales que históricamente han hecho vida en la Amazonía (véase el comunicado de respaldo a la implementación del AMO por parte del Consejo Popular Minero, 2017).

Contrariamente, la postura de las organizaciones indígenas se resumió de la siguiente manera:

“(...) Sabemos que el estado está en una emergencia, pero no podemos pagar las consecuencias(...) consideramos que el Arco Minero es una violación de nuestro derecho legítimo a la salud y a un territorio seguro, propio y con calidad de vida[...] Es el deseo expreso de esta XX Asamblea General Ordinaria de la Organización Kuyujani decir NO AL ARCO MINERO DEL ORINOCO, SI AL ¡BUEN VIVIR! en los territorios indígenas, solicitamos actuar conforme al marco legal previsto en la Constitución, las leyes, convenios, pactos y tratados de la República Bolivariana de Venezuela, y en consecuencia exigimos que mediante la presente, el Alto Mando Militar y la Presidencia de la República Bolivariana de Venezuela, también cumplan con sus obligaciones según dictan las leyes” (Kuyujani, 2016).

A partir de lo dicho, se profundizaron las articulaciones de las organizaciones indígenas amazónicas con aliados de los movimientos sociales y sectores académicos que, a través de figuras como Esteban Emilio Mosonyi, entonces rector de la Universidad Nacional Experimental Indígena del Tauca, Santiago Arconada y Edgardo Lander, miembros del Consejo Rectoral Provisional de la misma universidad, promovieron la ejecución de recursos legales para elevar el alcance de la demanda indígena hacia instancias nacionales. Así, se diversificaron los mecanismos de presión política dirigidos desde las organizaciones de base hacia el Estado, introduciéndose un recurso ante el Tribunal Supremo de Justicia(TSJ) el 31 de mayo de 2016 donde se solicitó expresamente la nulidad del AMO por considerase un "[...] acto normativo sub legal contrario a los principios del sistema constitucional y otros textos normativos venezolanos [...]" en materia de ordenamiento territorial, Derechos Humanos de los pueblos y comunidades indígenas amazónicas, protección del medio ambiente, derechos laborales y principios tributarios(Osorio, et al., 2016). ${ }^{8}$ Este recurso determinó el cierre de este primer momento, caracterizado por (1) la necesidad de las organizaciones indígenas de desmarcarse públicamente de la génesis política del AMO; y (2) la adopción de estrategias y lazos de influencia indirecta, pero de amplia repercusión, que permitieron a las organizaciones indígenas amazónicas elevar sus peticiones a instancias políticas más allá de la Amazonía.

\section{Segundo momento: institucionalización de la violencia paraestatal} y radicalización de las agencias indígenas (marzo de 2016 - presente)

En correspondencia con lo planteado por Collier y Hoeffler (2005), Ross (2006) y Obi (2010) para el caso africano; y Pedraza Saravia y Olaya (2011), Vélez-Torres y Ruiz-Torres (2015), Schneider (2016), Martínez Neira y Delamaza (2018), y otros autores para diversos contextos latinoamericanos, convenimos que los países/ 
regiones con recursos naturales estratégicos son potencialmente propensos a sufrir conflictos violentos. La institucionalización de la violencia en la Amazonía de Venezuela se agudizó consecuencia de los conflictos de intereses entre los cuerpos de seguridad del Estado, principalmente militares, y organizaciones paraestatales como guerrillas, sindicatos, pranatos, bandas armadas y otras formas de organización delictiva; así como por disputas en torno al control minero entre estas últimas organizaciones (Antillano, Fernández-Shawn y Castro, 2018).

La violencia asociada a la minería responde a profundas vinculaciones entre sectores estatales y organizaciones paraestatales que coexisten en un marco de tensión permanente donde la centralización de la función represiva se expande/contrae de acuerdo con una multiplicidad de intereses, actores y demandas contingentes (Romero y Ruiz, 2018). Algunas de estas organizaciones operan con relativa autonomía en las zonas mineras de los estados Bolívar, Amazonas y Delta Amacuro, asumiendo funciones coercitivas que muchas veces son toleradas por instancias militares en los territorios amazónicos. La minería ilegal, el contrabando de extracción de gasolina y otros combustibles derivados del petróleo, el tráfico de drogas y la comercialización de armas "de guerra" son algunas de las actividades que han institucionalizado las relaciones ilícitas entre el Estado y las organizaciones paraestatales que hacen vida en la región amazónica (Vutova, 2017).De esta forma, se tejió un sistema de relaciones donde las organizaciones paraestatales se disputan el control local de las comunidades mineras a fin de obtener posiciones de poder que les permitan negociar las condiciones de la actividad minera con decisores dentro del Estado venezolano (Ruiz, 2018). No obstante, las crecientes demandas del capital privado involucrado en el AMO han complicado las relaciones de poder preexistentes entre sectores estatales y paraestatales en la Amazonía, dando cabida a numerosos episodios de violencia que han afectado de manera directa a las comunidades indígenas asentadas en zonas de intensa minería.

Un hito reciente en la institucionalización de la violencia paraestatal en los territorios amazónicos enmarcados en el AMO lo constituyó la "Masacre de Tumeremo" ocurrida el 4 de marzo del año 2016, en la que desaparecieron y murieron veintiocho mineros producto de disputas violentas por el control local entre grupos paraestatales. Seguidamente, hechos de violencia de la misma naturaleza (amenazas, agresiones físicas, persecuciones, desapariciones forzadas y asesinatos) se han replicado en las comunidades indígenas asentadas en las zonas mineras del estado Bolívar, dando lugar a pronunciamientos y acciones de protesta por parte de las organizaciones y miembros de las comunidades afectadas. En este escenario se diversificaron las agencias indígenas adquiriendo importancia respuestas más espontáneas, caracterizadas por el uso de mecanismos "físicos” que potenciaron las demandas indígenas en materia de seguridad hacia la opinión pública y, consiguientemente, hacia las instituciones del Estado.

Así, acontecimientos como...

[1] "después de horas de negociación con el ejército, el Consejo de Caciques Generales [del Pueblo Pemón] consiguió establecer una colaboración con Redi Guayana, gracias a la cual se detuvo a setenta y seis delincuentes armados que pretendían tomar el control de la explotación ilegal del oro en la zona [Hacha Ken - Gran Sabana, estado Bolívar]” (Kapé Kapé, 2017).

[2] "comunidades indígenas trancaron la troncal 10, carretera internacional [con Brasil], en protesta por el presunto asesinato de dos de sus hermanos indígenas" (Soto, 2018a).

[3] "mineros desalojados por indígenas en compañía de un componente militar [...con motivo de] la desaparición de un indígena pemón [El Dorado, estado Bolívar]” (Soto, 2018b).

...dieron cuenta de una radicalización de las agencias indígenas en el ámbito local, así como la adopción de estrategias contingentes que permitieron a las organizaciones y comunidades hacer frente a las violencias procedentes de grupos irregulares. La emergencia de estos eventos fue reflejo de clausuras del espacio político entre grupos paraestatales y comunidades indígenas con el Estado. De esta forma, las acciones "por cuenta propia” o los estímulos direccionados desde "abajo hacia arriba” fueron síntoma del incumplimiento de las funciones de seguridad atribuidas al Estado, cuestión paradójica si se considera que la instalación del AMO estuvo precedida y sucedida por la militarización de los territorios amazónicos. ${ }^{9}$ 


\section{Tercer momento: criminalización de la protesta indígena en torno al conflicto pemón-Estado (junio de 2018 - presente)}

La reapertura al capital privado nacional e internacional demandó la creación de empresas mixtas entre sectores económicos del Estado, principalmente militares (como la Compañía Anónima Militar de Industrias Mineras, Petrolíferas y de Gas, CAMINPEG) y compañías extranjeras como la GR Mining de Barbados, Energold Mineral de Canadá, Marilyns Prje Yatirim de Turquía, Sakam y Comercializadora Orinoco River de Palestina. Simultáneamente, justificó la emergencia de alianzas y acuerdos de intención con corporaciones internacionales como la Gold Reserve y Barrick Gold International Corporación de Canadá, China CAMC Engineering de China, Bedeschi de Italia, Afridiam del Congo, Guaniamo Mining de EE.UU, entre otras, acentuando los conflictos de intereses entre los grupos paraestatales con operaciones en la minería ilegal y los sectores militares garantes de los acuerdos que involucraron capital privado, nacional e internacional, en la puesta en funcionamiento del AMO. ${ }^{10}$

La intervención del sector militar como cuerpo de seguridad del Estado, a la vez que un sector económico con intereses propios en la minería, trajo consigo un incremento de acciones violentas de este hacia líderes comunitarios y comunidades indígenas, así como hacia actores indígenas partícipes en la minería a pequeña escala, profundizando las dislocaciones entre organizaciones indígenas y Estado en el marco de una radicalización del conflicto “pemón-Estado”.

El 8 de junio de 2018 el Estado venezolano anunció la activación del operativo militar “Manos de metal” que buscaría desarticular alos grupos paraestatales dedicados a la explotación y comercialización ilegal de oro procedente delos territorios amazónicos de Venezuela. Acto seguido, un grupo de indígenas pemón protestó en la Casa Presidencial de la localidad de Manacrí, sede de varios comandos militares en la zona, en resistencia a una posible intervención a la alcaldía del municipio Gran Sabana por parte del partido de gobierno a fin de intensificar el control militar sobre las actividades mineras en el sur del estado Bolívar. Ambos hechos fueron sucedidos por declaraciones del militar General Roberto González Cárdenas quien acusó públicamente a los indígenas pemón de organizar un movimiento “secesionista” que amenazaba con menoscabar la soberanía nacional en los territorios de la Amazonía, argumento que ya había sido precedido en la voz de intelectuales notables cercanos al gobierno como el ensayista e historiador Luis Britto García. ${ }^{11}$ Esto trajo como consecuencia un incremento de intervenciones militares en los territorios amazónicos de Venezuela resultando, en diciembre del mismo año, en el asesinato de un indígena pemón en el sector Canaima y, posteriormente, en la retención de funcionarios militares por parte de las comunidades y organizaciones indígenas del municipio Gran Sabana quienes intensificaron sus acciones de protesta.

La intervención del sector militar en los territorios indígenas pemón se acompañó de una criminalización de su protesta contra el autoritarismo militar, violación de sus Derechos Humanos e incumplimiento de las obligaciones reservadas al Estado, traduciéndose en la voz de autoridades militares y representantes del gobierno como delitos de "secesión” y "traición a la patria” por parte de las comunidades, organizaciones y líderes pemón al sur de la Amazonía venezolana (ejemplo de esto puede observarse en las acusaciones dirigidas por el militar General Roberto González Cárdenas hacia la líder indígena Lisa Henrito quien fue catalogada de “amenaza” por su activismo al sur de la Amazonía venezolana). Al igual que en las últimas décadas del siglo XX, el Estado atribuyó la protesta indígena pemón a causas comunes como(1) falta de identidad nacional producto de su ubicación en áreas de frontera (Venezuela-Brasil); y (2) cierto matiz de ignorancia que los ha tornado vulnerables a manipulaciones políticas por parte de grupos y organizaciones contrarias a los intereses nacionales. Quizá, la diferencia radicó en el perfil ideológico atribuido a los supuestos “enemigos”, pasando de antropólogos e indígenas, desestabilizadores de izquierda y enemigos de la libre empresa en los años 80 (Arvelo-Jiménez, 1987), a antinacionalistas de derecha serviles a los intereses norteamericanos en el presente.

El reciclaje de estos argumentos buscó neutralizar la protesta indígena al descolocarla de un escenario de reivindicaciones político-sociales de los grupos étnicos hacia el Estado, para enmarcarla en un entramado de conflictos entre el Estado y actores internacionales considerados enemigos nacionales. El conflicto pemónEstado formó parte de una inmunización política a las oposiciones sociales que sucedieron la institucionalización del extractivismo minero a gran escala, haciendo que el incremento de la violencia estatal fuese más allá de 
circunstancias excepcionales. De hecho, forma parte de un condicionamiento impulsado desde las instituciones del Estado para avalar políticamente la redistribución de los recursos y territorios amazónicos desde los pueblos indígenas, hacia los sectores militares, empresas nacionales y corporaciones internacionales involucrados en el AMO, cuestión que socavó, todavía más, las fracturas entre E-OI-MS.

\section{La transición del voto indígena antes y después del AMO: el caso del estado Bolívar y su relación con la política nacional (2013-2017)}

La dislocación entre E-OI-MS se expresó en la pérdida de respaldo político dirigido al chavismo en los comicios electorales posteriores a la instalación del AMO. Esta depreciación se vio reflejada en los resultados de las elecciones municipales realizadas en 2017 donde los municipios del estado Bolívar con mayor población indígena (Gran Sabana con 59,9\%, Sucre con 29,4\%, Bolivariano de Angostura con 18,57\% y Sifontes con $18,48 \%$ de población indígena respecto al total) mostraron una debacle de los votos favorables al chavismo si se compara con los resultados de las mismas elecciones realizadas en $2013 .{ }^{12}$

En los municipios Gran Sabana, Sucre, Bolivariano de Angostura y Sifontes se observó una reducción porcentual del voto dirigido al chavismo en un42,59\%, 11,57\%, 13,56\% y 9,84\% respectivamente (véase la figura 3), siendo ésta su disminución más importante en el histórico electoral de los mencionados municipios. Como se aprecia en el siguiente gráfico la relación entre población indígena y popularidad electoral del chavismo es inversamente proporcional entre el período 2013-2017; es decir,el número de votos dirigidos al chavismo disminuyó en proporciones importantes en los municipios con mayor población indígena, cuestión que nos permitió relacionar su depreciación electoral con el descontento generalizado de las organizaciones y comunidades indígenas en torno a las devastaciones ocasionadas por el AMO.

Figura 3.

Variación de los votos del chavismo en los municipios indígenas del estado Bolívar (elecciones municipales 2013-2017)

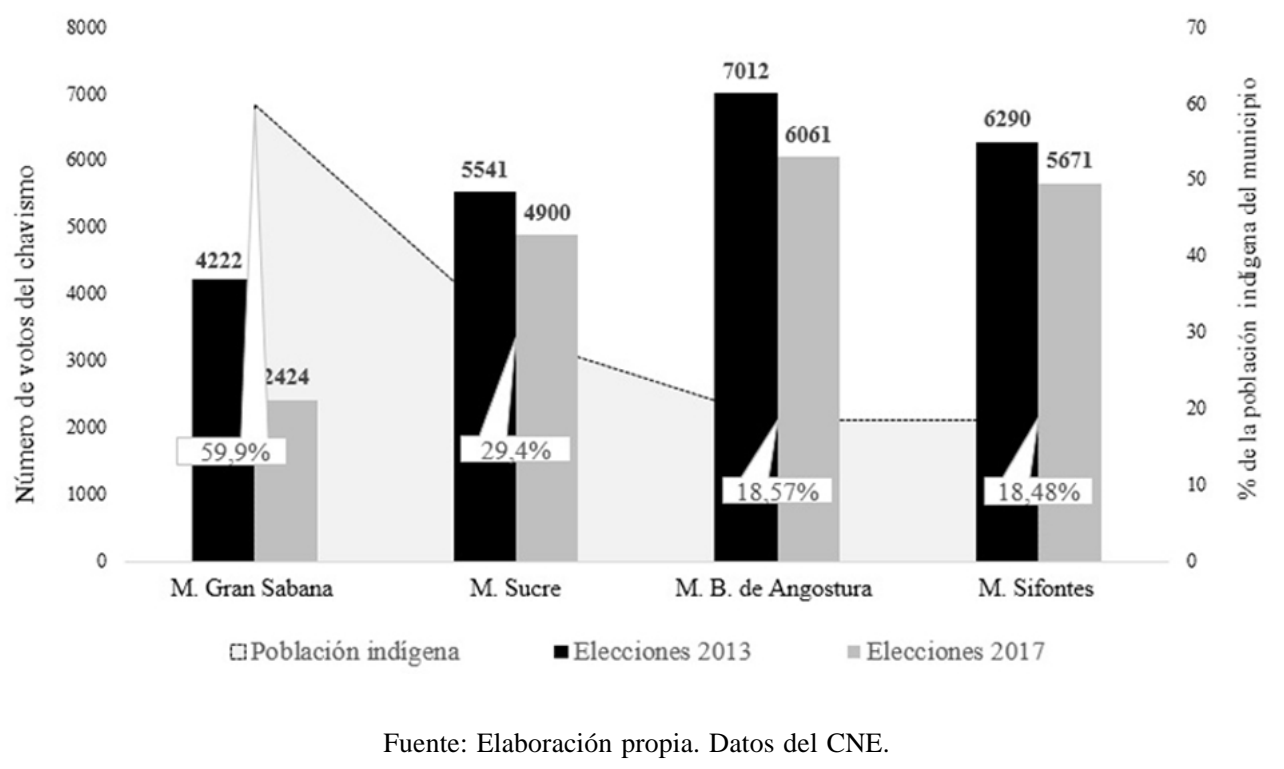

La merma del apoyo político dirigido al chavismo en los municipios indígenas del estado Bolívar conllevó a que, a diferencia de los últimos años, el municipio Gran Sabana eligiese como alcalde a un representante de una organización partidista de oposición al gobierno ?Emilio González de Independientes por el Progreso (IPP)?interrumpiendo la sucesiva elección de representantes alineados con el proyecto político del chavismo 
?miembros del Movimiento Quinta República (MVR), Patria Para Todos (PPT) y Partido Socialista Unido de Venezuela (PSUV)?los cuales dominaron la escena política del municipio Gran Sabana y del estado Bolívar desde la llegada de Hugo Chávez a la presidencia de la República (para un panorama general de la pérdida de apoyo electoral del chavismo a escala nacional véase a Hetland, 2016). Este singular acontecimiento complicó el desarrollo del conflicto pemón-Estado pues, la pérdida de control político del chavismo sobre dicho municipio aceleró la militarización de los territorios indígenas pemones y con ello, el control de las fuerzas represivas del Estado justificado en el combate de la minería ilegal y la prevención de movimientos secesionistas/ antinacionalistas por parte de las poblaciones indígenas al sur de la Amazonía de Venezuela.

Este cambio en la correlación de fuerzas políticas en los municipios indígenas del estado Bolívar formó parte de una estrategia de los sectores indígenas para elevarla exigibilidad de los derechos adquiridos en el contexto político del chavismo, potenciando así su capacidad de agencia al incidir en asuntos notables de la vida nacional como en este caso lo constituyeron las elecciones. Además de los desplazamientos forzados, el incremento de la violencia y el deterioro de las condiciones de vida de las comunidades indígenas posterior a la instalación del AMO; la política nacional también operó como un catalizador de la agencia indígena frente al AMO, complejizando en tejido de relaciones entre las propias organizaciones indígenas, y de estas con el Estado.

La política nacional también se configuró como un móvil de conflicto asociado al creciente intervencionismo del Estado venezolano en los territorios amazónicos. Así, entre 2013 y 2017, otros acontecimientos como la impugnación del TSJ a los diputados electos por el estado Amazonas y la representación indígena de la región sur (estados Bolívar, Apure y Amazonas) en las votaciones parlamentarias realizadas en 2015; la instalación de una Asamblea Nacional Constituyente (ANC) por parte de funcionarios del gobierno y sectores políticos afines al chavismo a mediados de 2017; y las protestas de sectores indígenas pemón contra lo que consideraron un fraude electoral contra el candidato Andrés Velásquez (LCR) al proclamarse a Justo Noguera Pietri (PSUV) como gobernador del estado Bolívar a finales del mismo año, profundizaron la fragmentación de las estrategias adoptadas por las organizaciones indígenas frente al AMO, y asuntos diversos referidos a la participación indígena en la política nacional.

Coaliciones indígenas como la Confederación Indígena Bolivariana de Amazonas (CIBA), que agrupa cerca de diez organizaciones del estado Amazonas, ${ }^{13}$ expresaron su rechazo al proceso constituyente impulsado por el chavismo a través de pronunciamientos públicos y protestas locales ${ }^{14}$ Lo mismo sucedió con organizaciones indígenas del estado Bolívar como el CCGPP. Paralelamente, miembros de ORPIA postularon y resultaron electos como representantes indígenas ante la ANC por la región amazónica, cuestión que fraccionó la agencia política de las organizaciones indígenas ante escenarios de polarización partidista. Pese a que la mayoría de las organizaciones indígenas acordaron en posiciones contrarias respecto al AMO, sus estrategias en la política nacional fueron diferentes. En el caso de organizaciones como ORPIA y PUAMA se observaron apuestas hacia un tipo de agencia "desde adentro" del Estado, caracterizada por la concientización y el dialogo en el marco de una mayor cercanía con los voceros e instancias de poder del chavismo en posiciones de gobierno. En el caso de otras organizaciones, como las integran la CIBA y algunas de las instancias deliberativas del pueblo pemón, entiéndase el CCGPP, se observaron apuestas hacia agencias "desde afuera” del Estado, caracterizadas por acciones de protesta y confrontación. Lejos de ser ontológicas, estas diferencias han sido versátiles y cambiantes en el tiempo, adaptadas a las contingencias, aunque, apegadas al carácter estructural y de larga duración de los sistemas de relacionamiento interétnico tradicionales en el norte amazónico.

En este escenario vale la pena preguntarse si, además de las estrategias particulares, existió cohesión en la posición de los indígenas frente al AMO. Las interpretaciones desde el Estado y los partidos políticos tradiciones abogarían por la imposibilidad de aceptar una cohesión interna entre las agencias que han tenido lugar desde adentro y afuera del Estado. En este caso, las acciones de los indígenas quedarían inscritas en la bifurcación partidista "gobierno/oposición”. Por otro lado, las lecturas desde abajo concebirían posible una cohesión interna más allá de las estrategias particulares. Alineados con la última premisa pensamos que las organizaciones indígenas se articularon y fragmentaron respondiendo desde distintos frentes a objetivos comunes: impedir el AMO y que, en correspondencia con lo planteado por el SIRO, las integraciones y segregaciones entre los indígenas fueron posibles siguiendo la complementariedad entre las organizaciones y actores que hacen vida en 
la Amazonía. Así mismo, la creciente de exigibilidad política de los actores indígenas hacia el Estado dio cuenta de cambios significativos en las formas de concebir y hacer política. En su diversidad, las agencias indígenas frente al AMO hicieron patente la necesidad de replantear el papel del Estado y las políticas dirigidas a los pueblos indígenas en el marco del chavismo, cuestión importante considerando que la sensibilidad a lo indígena fue un punto de inflexión para incentivar la crítica en los sectores de base que son o habían sido parte del chavismo.

Las articulaciones de sectores indígenas con instancias políticas externas, generalmente de corte partidista, resultan de relaciones verticales que se expanden y se contraen según las necesidades y posibilidades del momento. Sin embargo, las alianzas de las organizaciones indígenas con sectores políticos "pro gobierno” y "pro oposición” no reflejan posiciones concluyentes que transgreden del todo la autonomía e intereses propios con los que emergieron estas organizaciones pues, como se ha señalado, la exigibilidad de organizaciones amazónicas se ha mantenido en el tiempo, solo que, en determinados momentos, se expresó en un apoyo electoral irrestricto dirigido al chavismo(1999-2016), mientrasque en otros, el respaldo comenzó a erosionarse (2016-presente) consecuencia de quiebres de alianzas y disolución de intereses compartidos que mantuvieron más o menos estables las relaciones entre E-OI-MS antes del AMO.

\section{Conclusiones}

Esta investigación tuvo como objetivo estudiar el papel de la agencia indígena en el principal conflicto socioambiental que en la actualidad tiene lugar en la Amazonía venezolana, el AMO, buscando con ello llenar un vacío en la literatura científica de los últimos años que ha estudiado el fenómeno del AMO como un problema exclusivamente ambiental donde los indígenas, y lo indígena, ocupa un lugar secundario o inexistente. Al mismo tiempo, intentó trascender los análisis que, comprometidos ideológicamente, invisibilizaron las luchas indígenas en la Amazonía venezolana, representando las problemáticasen torno al AMO únicamente como (1) amenazas a la soberanía nacional en lo relativo a la administración de los recursos naturales, (2) complicaciones ambientales y (3) resistencias políticas de los sectores populares contra el capitalismo.

El AMO representó una ruptura de las organizaciones indígenas con el chavismo, en el plano político y electoral, situación que puso en tela de juicio los avances sociales, legales e institucionales que devinieron de la alianza que existió entre las organizaciones indígenas amazónicas y el chavismo a partir de la elección presidencial de 1998. Esta ruptura trajo consigo una fragmentación en las posturas de las organizaciones indígenas de la región que pueden resumirse la siguiente manera: (1) organizaciones indígenas que optaron por mantener sus lazos con los poderes del Estado, aunque oponiéndose a la política económica del AMO; (2) organizaciones que fueron cooptadas por sectores de poder dentro del chavismo y que, contrario a sus intereses, apoyaron irrestrictamente la puesta en marcha del AMO, (3) organizaciones indígenas que establecieron alianzas coyunturales con los partidos criollos de la tradicional alianza en oposición al chavismo y; (4) organizaciones indígenas que mantuvieron una postura de independencia y que se desmarcaron tanto del chavismo, como de su tradicional oposición por considerar que ambas propuestas son contrarias a sus intereses. Sin embargo, es necesario señalar que este mosaico de posturas, lejos de ser estáticas, mostraron una flexibilidad que les permitió pasearse de una posición a otra siguiendo los tradicionales esquemas de fragmentación y reorganización de las coaliciones interétnicas del norte amazónico descritos en el SIRO. Esta situación es representativa de la ruptura entre las organizaciones indígenas y el proyecto chavista puesto que, en años pasados, el apoyo del movimiento indígena al chavismo llegó a ser casi absoluto.

Es necesario decir que esta ruptura, en el plano político y electoral, no tuvo un impacto de las mismas proporciones fuera de los territorios amazónicos. A pesar de las alianzas que lograron establecer con movimientos sociales, ONG's, académicos e intelectuales, las luchas indígenas no lograron del todo posicionarse como un elemento central en la agenda política nacional. A lo sumo, llegaron a considerarse como un ejemplo de la creciente participación de los militares en los espacios de poder a lo interno del chavismo, o un problema vinculado a las amenazas que enfrenta la conservación de la Amazonía. Ambas narrativas relegaron a un segundo plano las demandas políticas de las organizaciones indígenas, solo a lo interno de los movimientos sociales ysectores universitarios el problema indígena logró posicionarse como una demanda de carácter nacional. 
Este conjunto de aspectos dio cuenta de los retos presentes y futuros que tienen las organizaciones indígenas frente al AMO, los cuales pueden sintetizarse en la necesidad de:(1) reorganizar una agenda política indígena unificada en su diversidad de intereses; (2) concretar una estrategia de lucha que permita establecer puentes de comunicación con la población criolla y hacerla participe de sus demandas y; finalmente, (3) (re)negociar las "reglas del juego político” que rigen los espacios de encuentro de las organizaciones indígenas con los actores gubernamentales, apostando a un cambio en la direccionalidad de los procesos deliberativos sobre los asuntos indígenas por parte de las instituciones del Estado.

\title{
Notas
}

\begin{abstract}
${ }^{1}$ Las políticas dirigidas hacia los pueblos indígenas entre las décadas del 70 y 90 mostraron rasgos y características comunes, entre ellas, el aprovechamiento económico de las extensiones de tierra ocupadas por los indígenas (a través del fomento de industrias basadas en la producción de energía, minería, turismo, agricultura, etc.); tutelas misionales e inserción de los indígenas al mercado criollo en sus circuitos laborales formales e informales. El provecho económico la Amazonía venezolana trajo consigo un reordenamiento de los actores que tradicionalmente hicieron vida en estos contextos, avivando conflictos que resultaron de la convergencia de intereses y capitales que complejizaron las relaciones entre los indígenas, y de estos con actores e instituciones foráneos: militares, transnacionales, propietarios particulares, mineros legales e ilegales, guerrilleros, etc.
\end{abstract}

${ }^{2}$ También destacó la creación de otras organizaciones indígenas como la Unión Guahiba Venezolana (UNUMA); la Unión Kurripaco del Rio Atabapo (UkRA); la Organización Indígena Yabarana del Parucito Medio (OIYAPAM); la Asociación de Maestros Indígenas de Amazonas (ASOMIA); la Asociación Piaroas Productores de Cacao (APIPROCA); la Empresa Piaroas Productores de Miel (EPIAMIEL); la Asociación de Turismo Ecológico de los Pueblos Indígenas de Amazonas (ATEPIA), etc.

${ }^{3}$ Las “Federaciones Indígenas Regionales” creadas en los años 70 fueron muestra de este problema, algunas de ellas estuvieron bajo el control de actores vinculados a intereses partidistas dificultando la integración de los indígenas en torno a objetivos comunes.

${ }^{4}$ El SIRO constituye una propuesta teórica a para poder explicar el sistema de articulaciones interétnicas que durante siglos se ha creado y recreado entre los grupos indígenas que hacen vida en el norte de la Amazonía. La tesis de esta propuesta defiende la existencia de una complementariedad política y económica entre los grupos étnicos que habitan los biomas del norte amazónico (sabanas, riberas inundables del río Orinoco y zona inter fluvial de las Guayanas), cuyos recursos han sido insuficientes para cubrir del todo las necesidades de los grupos obligando al establecimiento de redes de intercambio a lo largo y ancho de la cuenca del río Orinoco, sin que esto significase una pérdida de autonomía local, diversidad cultural o competencias lingüísticas de los grupos particulares al interior del sistema.

${ }^{5}$ [a] Hasta el 2016 no se registraron casos de infectados con sarampión. [b] El 80,58\% de los casos de paludismo en todo el país durante el 2017 se ubicaron en los estados Bolívar y Amazonas (OPS y OMS, 2018a). [c] El 82\% de los casos de sarampión se registró en el estado Bolívar y la diseminación estuvo asociada al elevado movimiento migratorio generado por la actividad minera (OPS y OMS, 2018b). Se desconoce el número de infectados con sarampión en los estados Amazonas y Delta Amacuro. Sin embargo, Delta Amacuro se encontró entre los cinco estados más afectados por la enfermedad en 2017. [d] Se confirmaron 535 casos de enfermos de sarampión en poblaciones indígenas durante 2018. En el estado Amazonas y Delta Amacuro se registraron 170 y 341 respectivamente. Adicionalmente, se registraron 646 defunciones por sarampión a nivel nacional de las cuales 37 fueron en Delta Amacuro, todas del pueblo indígena Warao, y otras 27 de diferentes pueblos indígenas de Amazonas (OPS y OMS, 2018b). [e] La reducción de los casos de infectados por sarampión entre 2017 y 218 en el estado Bolívar obedece a estrategias de vacunación (OPS y OMS, 2018b).

${ }^{6}$ De acuerdo con datos oficiales de la agencia de la Organización de las Naciones Unidas para Refugiados (UNHCR) las entidades Bolívar, Amazonas y Delta Amacuro aportan una cifra importante de los desplazados y refugiados que acuden a Brasil (2018).

${ }^{7}$ A las que se suman la Organización Yé kwana del Alto Ventuari (KUYUNU), la Organización Indígena Jivi Kalievirrinae (OPIJKA) y la Organización de Mujeres Indígenas Amazónicas (WANAALERU), principalmente.

${ }^{8}$ El recurso fue introducido por la Plataforma por la Nulidad del Decreto del Arco Minero del Orinoco.

${ }^{9}$ Con motivo de la masacre de Tumeremo, el 8 de marzo de 2016, el presidente Nicolas Maduro decretó la creación de una "Zona Militar Especial” para asegurar la protección a los municipios mineros involucrados en el AMO.

${ }^{10}$ En un documento oficial,la Gold Reserve anunció que su instalación en el estado Bolívar a través de la empresa mixta Siembra Minera requeriría de "[...] the conceptual plan includes relocation of the artisanal miners away from the active, large scale mining operations” (Gold Reserve INC., 2018: 4), situación que promete complicar las tensiones entre las organizaciones locales participes de la minería ilegal en zonas cercanas a Las Brisas y Las Cristinas, los cuerpos de seguridad del Estado venezolano y representantes de los intereses del capital internacional.

${ }^{11}$ En un artículo de opinión del 23 de julio de 2017, Luis Britto García aseveró que la existencia de pueblos distintos del venezolano, con organizaciones políticas propias y tierras cuyos recursos el Estado no puede explotar sin consulta "[...] estaría sentando las bases 
para que, previa declaratoria de independencia, una generosa potencia extranjera los proteja y nos secesione en varias decenas de países” (véase “Constitución y Unidad Nacional” de Britto García, 2017).

${ }^{12}$ Estos datos se extrajeron del XIV Censo Nacional de Población y Vivienda realizado en 2011.

${ }^{13}$ La CIBA agrupa a organizaciones como la Organización del Pueblo Indígena Uhuottuja de la Cuenca del Cataniapo (OPUHC), la Organización de Profesionales del Pueblo Uhuottuja (OPROPIU), la Organización del Pueblo Indígena Kurripaco de Carinagua (OPICA), la Unión de Comunidades Indígenas Uhuottuja del Parhuaza (UCIUSPA), la OPIJKA, entre otras.

${ }^{14}$ Antes del AMO, en el estado Amazonas ya habían tenido lugar quiebres electorales de los sectores indígenas con los candidatos locales propuestos por el chavismo. Desde 2010, fue posible el voto mayoritario hacia los candidatos presidenciales Hugo Chávez (2012) y Nicolas Maduro (2013), a la vez que fue electo como gobernador del estado Liborio Guarulla (líder indígena del pueblo baniva) en representación de coaliciones partidistas de oposición al chavismo.

\section{Bibliografía}

Alès, C. (2018). From proclamation to denial. Indigenous rights and political participation in Venezuela. Regions \& Cohesion, 8(2), 49-81. DOI: 10.3167/reco.2018.080204.

Angosto, L. F. (2008). Pueblos indígenas, guaicaipurismo y socialismo del siglo XXI en Venezuela. Antropológica de la Fundación La Salle de Ciencias Naturales, 52(110), 9-33. Recuperado de http:// www.fundacionlasalle.org.ve/userfiles/2-Articulo\%20pag\%209-33.pdf

Antillano, A., Fernández-Shaw, J. y Castro, D. (2018). No todo lo que mata es oro: La relación entre violencia y rentas mineras en el Sur del Estado Bolívar. En K. Gabbert y A. Martínez (Comps.),Venezuela desde Adentro: ocho investigaciones para un debate necesario (pp. 145-189). Quito, Ecuador: Fundación Rosa Luxemburgo.

Arvelo-Jiménez, N. (1984). The politics of cultural Survival in Venezuela: Beyond Indigenismo. En M. Schmink y C.Wood (Eds.),Frontier expansion in Amazonia(pp. 105-126).Gainsvtille, United States: University of Florida Press.

Arvelo-Jiménez, N. (1987). Se dice que son contradictorios... Los indígenas y la Seguridad Nacional. En C. Mora y C. Aramburu (Eds.),Desarrollo amazónico: una perspectiva latino-americana(pp. 391-423). Lima, Perú: Centro de Investigación y Promoción Amazónica - Instituto Andino de Estudios en Población y Desarrollo.

Arvelo-Jiménez, N. (2013). Movimientos etnopolíticos contemporáneos y sus raíces organizacionales en el Sistema de Interdependencia Regional del Orinoco. Anuario Antropológico, 2. DOI: 10.4000/aa.1276

Arvelo-Jiménez, N., Morales, F. y Biord, H. (1989). Repensando la historia del Orinoco. Revista de Antropología, 5, 155-174.

Arvelo-Jiménez, N., y Biord, H. (1994). The Impact of Conquest on Contemporary Indigenous Peoples of the Guiana Shield: the System of Orinoco Regional Interdependence. En A. Roosevelt (Org.), Amazonian Indians from Prehistory to the Present: Anthropological Perspectives (pp. 55-78). Tucson \& London: The University of Arizona Press.

Biord Castillo, H. (2010). La colonisation de la région amazonienne au Venezuela (1960-2000). En D. Sayago, et al. (Comps.), L’Amazonie: Un demi-siècle après la colonisation.Versailles, France: Editions Quæ. DOI: https://doi.org/10.3917/quae.doris.2010.01.0083

Bracho, F. (2008). Lo “socialista” como enemigo de lo indígena: el caso venezolano. Polis. Revista Latinoamericana, 19, s.p. Recuperado de https://journals.openedition.org/polis/3938

Britto García, L. (2017). Constitución y Unidad Nacional. Recuperado de http://luisbrittogarcia.blogspot.com/ 
2017/07/blog-post_23.html

Caballero Arias, H. (2007). La Demarcación de Tierras Indígenas en Venezuela. Revista Venezolana de Economía y Ciencias Sociales, 13(3), 189-208. Recuperado de http://www.scielo.org.ve/ scielo.php?script=sci_arttext\&pid=S1315-64112007000300013

Caballero Arias, H. (2018). Escenarios de lo político: Movilización y participación política indígena en el estado Amazonas, Venezuela. Fermentum. Revista Venezolana de Sociología y Antropología (28), 406-442. Recuperado de http://www.saber.ula.ve/handle/123456789/45580

Cannon, B. y Brown, J. (2017). Venezuela 2016: the year of living dangerously. Revista de CienciaPolítica, 37(2), 613-633.

Collier, P. y Hoeffler, A. (2005). Resource rents, governance, and conflict. Journal of conflict resolution, 49(4), 625-633. Recuperado de https://www.jstor.org/stable/30045133

Consejo Popular Minero (2017). Comunicado. Consejo Popular Minero respalda implementación del Arco Minero del Orinoco. Recuperado de http://mppre.gob.ve/wp-content/uploads/2017/11/Comunicado-del-Consejo-Popular-Minero_19-11-2017.pdf

García-Guadilla, M. P. (2009). Ecosocialismo del siglo XXI y modelo de desarrollo bolivariano: los mitos de la sustentabilidad ambiental y de la democracia participativa en Venezuela. Revista Venezolana de Economía y Ciencias Sociales, 15(1), 187-223.Recuperado de http://www.scielo.org.ve/pdf/rvecs/v15n1/art10.pdf

Giddens, A. (2014). Studies in Social and Political Theory. Londres, UK: Routledge.

Gold Reserve INC. (2018). Technical report on the "Siembra Minera” Project, Bolivar State, Venezuela. Recuperado dehttps://www.goldreserveinc.com/wp-content/uploads/2018/04/RPA-GRI-Siembra-Minera-NI-43-101-PEAFINAL-2-Mar-16-2018.pdf

Hetland, G. (2016). From System Collapse to Chavista Hegemony. The Party Question in Bolivarian Venezuela. Latin American Perspectives, 212(44), 17-36. DOI: 10.1177/0094582X16666018

Kapé Kapé (2017). Grupo de 70 delincuentes secuestró a comunidad indígena de la Gran Sabana.Recuperado dehttps://kape-kape.org/2017/10/11/grupo-de-70-delincuentes-secuestro-a-comunidad-indigena-de-la-gransabana/

Krzywicka, K. (2011). Situación jurídica de los pueblos indígenas en Venezuela. Dilemas de representación y participación. Revista del CESLA, 14, 73-107. Recuperado de http://www.redalyc.org/ articulo.oa?id=243322672007

Kuyujani (2016). Comunicado de la organización Kuyujani. Recuperado dehttps://www.aporrea.org/pachamama/ n290187.html

Martínez Neira, C. y Delamaza, G. (2018). Coaliciones interétnicas, framing y estrategias de movilización contra centrales hidroeléctricas en Chile: ¿Qué podemos aprender de los casos de Ralco y Neltume? Middle Atlantic Review of Latin American Studies, 2(1), 68-96. DOI: 10.23870/marlas.180

Mitnick, B. M. (2015). Agency theory. Wiley encyclopedia of management, 1-6.

Obi, C. I. (2010). Oil extraction, dispossession, resistance, and conflict in Nigeria's oil-rich Niger Delta. Canadian Journal of Development Studies/Revue canadienned'études du développement, 30(1-2), 219-236.Recuperado de https://www.tandfonline.com/doi/abs/10.1080/02255189.2010.9669289

Oldham, P. (2003). Representación y organización política moderna de los indígenas de Amazonas: una re-evalua- 
ción. En C. Alés, y J. Chiappino, (Eds.),Caminos Cruzados: Ensayos en Antropología Social, Etnoecología y Etnoeducación(pp. ). Mérida, Venezuela: IRD Editions - ULA Grial.

OMS y OPS (2017). Alerta Epidemiológica: Aumento de casos de malaria. Recuperado de https://www.paho.org/ hq/dmdocuments/2017/2017-feb-15-phe-alerta-epi-malaria.pdf

OMS y OPS (2018a). Actualización epidemiológica: Aumento de malaria en las Américas. Recuperado dehttps:/ /www.paho.org/hq/index.php?option=com_docman\&view=download\&category_slug=20189582\&alias=43437-30-enero-2018-malaria-actualizacion-epidemiologica-437\&Itemid=270\&lang=en

OMS y OPS (2018b). Actualización epidemiológica: Sarampión. Recuperado de https://www.paho.org/hq/ index.php?option=com_docman\&view=download\&category_slug=sarampion-2183\&alias=47165-30-denoviembre-de-2018-sarampion-actualizacion-epidemiologica\&Itemid=270\&lang=en

Osorio, A. E. et al. (2016). Recurso de nulidad por ilegalidad e inconstitucionalidad al AMO. Recuperado de https://www.aporrea.org/media/2016/09/recurso_de_nulidad._arco_minero.pdf

Palau, D. E. (2001). Los pueblos indígenas del Amazonas venezolano desde Humboldt a nuestros días: preservación del ambiente y manejo sostenible. Northeastern Naturalist, 8, 135-156. Recuperado de https:// www.jstor.org/stable/4130731

Pedraza, H. y Olaya, A. (2011). Regalías, cooperativas y finanzas paramilitares en la costa caribe. En M. Romero Vidal (Coord.),La economía de los paramilitares: redes de corrupción, negocios y política(pp. 191-263). Bogotá, Colombia: Debate.

Prensa Presidencial (2016). Maduro: Política del Arco Minero es soberana, ecologista y 60\% de las ganancias obtenidas irán a misiones sociales.Recuperado de https://www.aporrea.org/economia/n294959.html

Puente, J. M. (2016). Petróleo y revolución: Venezuela 1999-2013. En T. Straka, (Comp.), La Nación petrolera, 1914-2014 (pp. 319-332). Caracas, Venezuela: Universidad Metropolitana - Academia Nacional de la Historia.

Romero, C. y Ruiz, F. J. (2018). Dinámica de la Minería a pequeña escala: dislocaciones y ramificaciones entre lo local y lo nacional. En, K. Gabberty A. Martínez (Comps.),Venezuela desde Adentro: ocho investigaciones para un debate necesario (pp. 87-143).Quito, Ecuador: Fundación Rosa Luxemburgo.

Ross, M. (2006). A closer look at oil, diamonds, and civil war. Annu. Rev. Polit. Sci., 9, 265-300. Recuperado de https://www.annualreviews.org/doi/abs/10.1146/annurev.polisci.9.081304.161338

Ruiz, F. J. (2018). El Arco Minero del Orinoco: Diversificación del extractivismo y nuevos regímenes biopolíticos. Nueva Sociedad, (274), 129-141. Recuperado de http://nuso.org/articulo/el-arco-minero-delorinoco/

Schneider, A. (2016). Economía, política y conflictividad minera durante las presidencias de Evo Morales en Bolivia (2006-2016). PerfilesEconómicos, 1, 83-118. Recuperado de https://revistas.uv.cl/index.php/Perfiles/article/view/608

Smilde, D. (2015). The End of Chavismo? Current History, 49-55. Recuperado de https://www.wola.org/sites/ default/files/Venezuela/Smilde\%20Current\%20History—final.pdf

Soto, S. (2018a). Troncal 10 trancada por desaparición de indígenas. Recuperado de https:// www.elcorreodelorinoco.com/troncal-10-trancada-desaparicion-indigenas/

Soto, S. (2018b). Desalojan a mineros en El Dorado. Recuperado de https://www.elcorreodelorinoco.com/desalojan-a-mineros-en-el-dorado/ 
Svampa, M. (2010). Movimientos Sociales, matrices socio-políticos y nuevos escenarios en América Latina. En One Word Perspective. Alemania: Universitat Kassel.

Terán Mantovani, E. (2016). Las nuevas fronteras de las commodities en Venezuela: extractivismo, crisis histórica y disputas territoriales. Ciencia Política, 11(21), 251-285. DOI: https://doi.org/10.15446/cp.v11n21.60296

Terán Mantovani, E. (2018). Naturaleza y territorialidades en disputa: los ecologismos populares venezolanos y el ecosocialismo realmente existente en la Revolución Bolivariana. En K. Gabbert y A. Martínez (Comps.),Venezuela desde Adentro: ocho investigaciones para un debate necesario (pp. 17-84). Quito, Ecuador: Fundación Rosa Luxemburgo.

Tillet, A. y Moncada, A. (2017). Las organizaciones indígenas y la lucha por la defensa de sus territorios en el estado Amazonas. Territorios Comunes, 1, 71-76. Recuperado de http://www.ecopoliticavenezuela.org/2018/ 01/22/las-organizaciones-indigenas-y-la-lucha-por-la-defensa-de-sus-territorios-en-el-estado-amazonas/

UNHCR (2018). Venezuela (Fact Sheet).Recuperado dehttp://reporting.unhcr.org/sites/default/files/ UNHCR\%20Venezuela\%20Fact\%20Sheet\%20-\%20September\%202018.pdf

Valladares, R. Sandia, L. (2017). Legislación ambiental aplicable a las actividades mineras en Venezuela. Gestión y Ambiente, 20(2), 253-264. DOI: https://doi.org/10.15446/ga.v20n2.63180

Van Cott, D. L. (2002). Movimientos indígenas y transformación constitucional en los Andes. Venezuela en perspectiva comparativa. Revista Venezolana de Economía y Ciencias Sociales, 8(3), 41-60. Recuperado de https://www.ecopoliticavenezuela.org/biblioteca/libros/movind/

Vélez-Torres, I., y Ruiz-Torres, G. (2015). Extractivismo neoliberal minero y conflictos socio-ambientales en Perú y Colombia. Ambiente y Sostenibilidad, 5, 3-15. Recuperado de http://revistas.univalle.edu.co/index.php/ ays/article/download/4297/6517/

Vutova, M. (2017). Migrantes, desterrados, intrusos. Navegando la frontera amazónica entre Venezuela y Colombia. Confluenze, 9(1), 107-122.Recuperado de https://confluenze.unibo.it/issue/view/633 